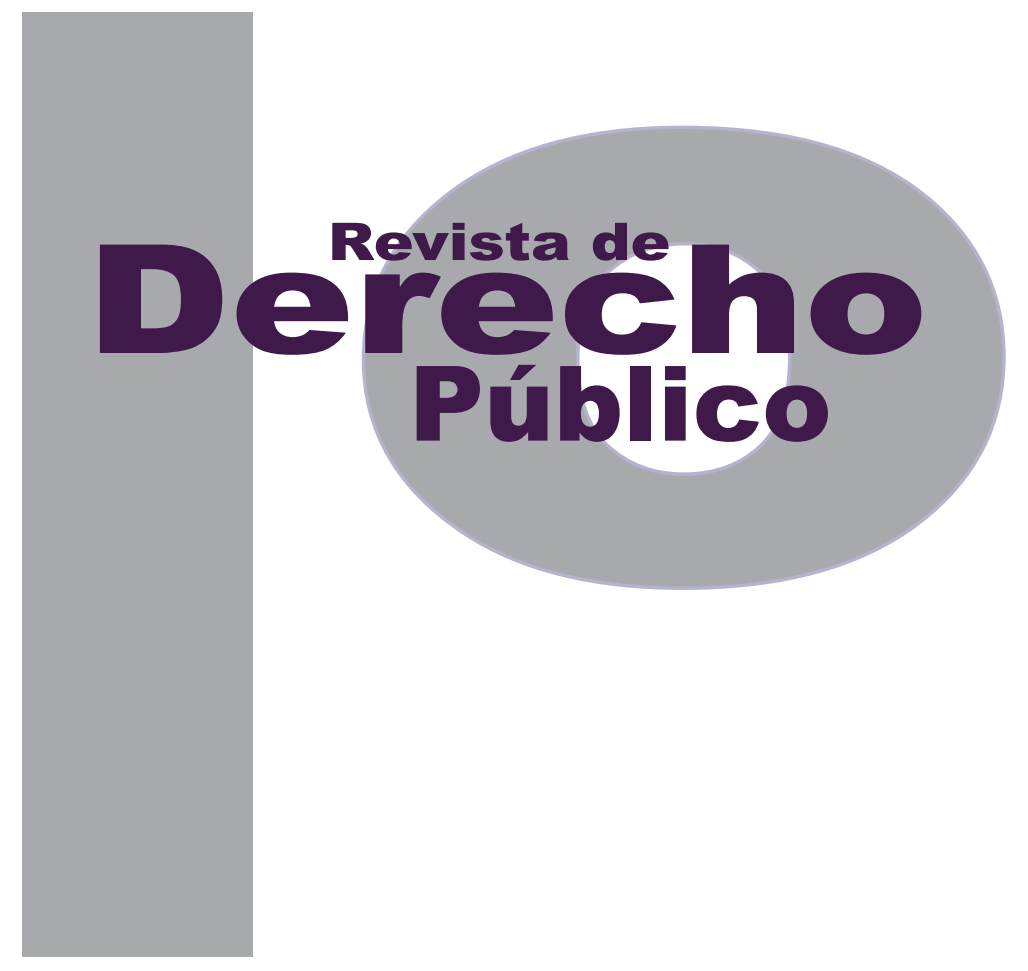

\title{
EL TRATO DIGNO A LA VÍCTIMA EN EL PROCESO JUDICIAL
}

\author{
Citlali Urtiz \\ Carlos Manuel Rosales \\ Revisión de tema \\ DOI: http://dx.doi.org/10.15425/redepub.33.2014.02
}

Universidad de los Andes

Facultad de Derecho

Revista de Derecho Público N. ${ }^{\circ} 33$

Julio - Diciembre de 2014. ISSN 1909-7778 


\section{El trato digno a la víctima en el proceso judicial}

\section{Resumen}

El presente trabajo tiene por objeto presentar y analizar los elementos y herramientas que requiere un juez y su personal para desempeñar sus funciones y, sobre todo, tratar con dignidad a la víctima. Por lo tanto, se analizará la utilización de diversos principios y protocolos que deben regir su actuación.

Palabras clave: justicia, tribunales, jurisdicción, principios rectores judiciales.

\section{The dignified treatment to the victim in the judicial process}

\section{Abstract}

The present work has for aim to present and analyze what elements and tools a judge and his team need to perform functions and to treat the victim with dignity. Every Court requires the use of several principles and protocols that must rule its action.

Keywords: justice, courts, jurisdiction, governing judicial principles.

\section{0 tratamento digno à vítima no processo judicial}

\section{Resumo}

O presente trabalho tem como objetivo apresentar e analisar os elementos e ferramentas que um juiz e seu pessoal requerem para desempenhar suas funções e, principalmente, tratar à vítima com dignidade. Portanto, será analisada a utilização de diversos princípios e protocolos que devem reger sua atuação.

Palavras-chave: justiça, tribunais, jurisdição, princípios reitores judiciais. 


\title{
El trato digno a la víctima en el proceso judicial*
}

\author{
Citlali Urtiz* $^{* *}$ \\ Carlos Manuel Rosales ${ }^{* * *}$
}

\section{SUMARIO}

Introducción - I. NATURALEZA Y FIN DE LOS PRINCIPIOS NORMATIVOS - A. Imparcialidad - B. Independencia - C. Legalidad - D. Objetividad - E. Publicidad - II. CONCLUSIONES - Referencias.

* Cómo citar este artículo: Urtiz, C. y Rosales, C. M. (Diciembre, 2014). El trato digno a la víctima en el proceso judicial. Revista de Derecho Público, 33. Universidad de los Andes (Colombia).

** Licenciada en Psicología y diplomada en Psicología Forense por la Universidad Nacional Autónoma de México. Magíster en Victimología por el Instituto Nacional de Ciencias Penales.

*** Licenciado en Derecho por la Universidad Nacional Autónoma de México. Diplomado por la Universidad de Heidelberg. Magíster y Doctorado en la Universidad de Chile. 
Introducción

La realización de un delito implica el daño o menoscabo físico, psicológico o económico a una persona, lo que conllevó reconocer al afectado como víctima u ofendido. Sin embargo, el concepto de víctima fue poco atendido por la ciencia jurídica después de que fue secularizada la venganza, pues se consideraba que con la venganza privada, la reparación del daño, una multa o una sentencia se había cumplido con el deber de suministrar un castigo al acusado por aquella conducta delincuencial, dando por satisfecho el interés de la víctima y de la sociedad. ${ }^{1}$

Con la evolución del derecho penal se le dio mayor importancia a la víctima (Zamora, 2009, p. 23), pues su actuación se basaba principalmente en presentar la denuncia y ser la prueba visible de que se había cometido un delito, pero no era considerada parte activa en el proceso, por lo que se reconoció que tenía derecho a asistencia legal y médica, y posteriormente la facultad de poder participar en el proceso penal.

Con el establecimiento del Estado se constituyó que uno de sus fines es brindar seguridad y protección a los derechos y libertades de la población, para lo cual se necesitaba establecer un conjunto de leyes e instituciones públicas, pues "un Estado se justifica, si protege los derechos y libertades de los gobernados" (Nieto, 2003, p. 134).

1 Deseamos agradecer las entrevistas, comentarios y disposición de la maestra en Derecho Constitucional María Magdalena Castillo Meza, quien nos compartió sus valiosos conocimientos y agradable compañía.
El objetivo de implantar un sistema de administración de justicia en un régimen democrático es resolver imparcial y públicamente, a través de tribunales independientes y de la regulación de procedimientos jurisdiccionales, los conflictos expuestos y, consecuentemente, determinar las sanciones correspondientes (Ponce de León, 1997, p. 7).

Pero la evolución del derecho, y en especial el reconocimiento de las víctimas, llevó no solo a una reparación del daño o menoscabo sufrido, sino a que tuvieran un trato basado en la dignidad, por parte de los operadores jurídicos (De la Mirándola, 1984, pp. 37, 121, 148, 170 y ss.), es decir, a que se les diera un tratamiento especial por su problema, menoscabo o traumatismo; que las autoridades públicas fueran respetuosas; que estuvieran atendidas por profesionales con base en protocolos especializados; y provocar una sensibilidad pero sin desequilibrar o conculcar los derechos del victimario. Así, el derecho a la dignidad de la víctima se consagró no solo como un derecho legal, sino como el reconocimiento al honor de la persona como ser humano (Robertson, 1997, pp. 81-172).

Este trabajo de investigación tuvo por objetivo averiguar qué principios jurisdiccionales deberán regir la actuación de los jueces y magistrados, para que la víctima sea tratada con dignidad, que el proceso de revictimización cauce menos tribulación, pero sobre todo, que la víctima sienta satisfecha su exigencia de justicia.

En primer lugar, se expondrá la naturaleza y la función jurisdiccional de los tribunales; en se- 
gundo lugar, se analizará la utilidad de los principios en materia de impartición de justicia; posteriormente, se presentará y examinará un conjunto de principios que deben regir la actuación jurisdiccional de los magistrados; y finalmente, unas conclusiones que resumirán y comprobarán la importancia de estos principios judiciales para que la víctima reciba un trato basado en la dignidad y el respeto, y pueda recuperar lo antes posible su calidad de vida.

\section{NATURALEZA Y FIN DE LOS PRINCIPIOS NORMATIVOS}

La manifestación más concreta de la justicia en todo sistema social es la correcta aplicación de las leyes, y la posibilidad de proteger su cumplimiento y respeto a través de instancias que permitan resolver las controversias, conflictos y diferencias que se susciten (Andrade, 2002, p. 601).

Para que haya una seguridad jurídica eficaz "se necesita que las reglas sean públicas, generales, abstractas, relativamente estables, claras, no contradictorias, entre otros rasgos" (Orozco, 2006, p. 239).

Según el Tribunal Electoral del Poder Judicial de la Federación de México (TEP JF), algunos de los elementos esenciales de un tribunal son:

1. Debe ser jurídico, debido a que su finalidad es garantizar la vigencia del Derecho.

2. Cualquier conflicto surgido por la inobservancia de las normas jurídicas debe ser resuelto, no por la vía de construir para cada asunto una solución política negociada, sino imponiendo siempre la auténtica obediencia del derecho preestablecido y,

3. Debe ser efectivo, eficiente, disponible y accesible para todo actor, de manera que con independencia de la fuerza política que tenga pueda solicitar y obtener el pleno respeto de sus derechos (2003, 56-75).

Las características institucionales que en concepto del TEP JF (2003) debe tener un tribunal son:

- Ser especializado, esto es, que el trabajo debe ser realizado por profesionales en lo jurisdiccional, con el fin de promover niveles crecientes de eficiencia en el desempeño de sus funciones ( $p$. 59).

- Tener la labor de declarar el Derecho aplicable para resolver los conflictos que se presenten con motivo de los negocios a cargo del tribunal (p. 60).

- Garantizar: “1. el ejercicio republicano del poder público evitando que una sola instancia lo concentre con el riesgo de abusar de él y, 2. que las citadas funciones se realicen de manera especializada, atendiendo solo a los principios de cada una" (p. 61).

- Contar con autonomía funcional, ya que actuará sin subordinación institucional a órgano alguno. La autonomía normativa faculta el poder de dictar él mismo, las normas generales que reglamentan su funcionamiento interno (pp. 62 y 63). 
- Gozar con cierta autonomía administrativa, en razón de que le corresponde, con exclusividad, la atribución de manejar sus recursos, determinando a qué prioridades comprendidas dentro de su competencia deberán aplicarse los recursos humanos, materiales y financieros a su disposición (Lowenstein, 1964, pp. 232-251 y 294-325).

Lo anterior justifica la pertinencia y finalidad del poder judicial.

Los tribunales deben contar con el reconocimiento del Estado para aplicar las normas, función que ejercen a través de la jurisdicción, es decir, la atribución positiva que poseen para impartir justicia. Su validez de actuación se basa en la jurisdicción, que es entendida como "el conjunto de atribuciones que tiene el Estado, para ejercerlas, por conducto de alguno de sus órganos o por medio de árbitros, con aplicación de normas jurídicas generales e individualizadas a los diversos actos y hechos que se susciten con motivo del planteamiento de posiciones concretas en controversia" (Arellano, 1992, p. 346).

Contar con una adecuada jurisdicción representa seguridad jurídica para la población, puesto que garantiza que "el ejercicio del poder público esté restringido por reglas jurídicas" (Orozco, 2006, p. 237) $)^{2}$ e implica que los jueces deben realizar su labor de manera idónea, contar con preparación y reputación (requisito de calificación), y requisitos para su designación, tenencia

2 Véase Pérez Luño (1991) del cargo, remuneración y destitución (aislamiento) (Ansolabehere, 2007, p. 98).

Ahora es menester presentar los principios y reglas con base en los cuales los tribunales llevan a cabo sus cometidos.

El profesor Ronald Dworkin (1995) define el término "principio" como una pauta que ha de observarse, porque es una exigencia de la justicia, de la equidad o de otro aspecto de la moral, que es extrajurídica y vinculante para el juez. Así mismo, este autor considera que "Ios principios inclinan la decisión en una dirección, aunque no de manera concluyente, y sobreviven intactos aun cuando no prevalezcan" (pp. 19-22). ${ }^{3}$ Además de que "son la base que construyen los sistemas jurídicos, irradiándose a todo el sistema jurídico" (p. 77). ${ }^{4}$

Los principios son abstractos, de contenido impreciso e incierto, y han llegado para quedarse porque constituyen "los presupuestos que hacen posible a la democracia; además de que se establecen como un vínculo preventivo, que se autoimpone la comunidad para autoprotegerse y no perder el rumbo" (Salazar, 2007, p. 42).

Para Manuel Atienza (2005), los principios tienen las siguientes funciones:

3 Véase Bix (2004, p. 88)

4 Dworkin hace una distinción entre principios y normas: las normas jurídicas prescriben una conducta con su consecuencia jurídica; los principios carecen de dicha consecuencia en razón de que se trata de planteamientos que ayudan a tomar posición ante los casos concretos, son orientadores, estándares de conducta, por lo tanto los principios son superiores a la norma. Véase Orozco (2006, pp. 255-280). 
1. Función creativa: antes de promulgar la norma jurídica, el legislador debe conocer los principios para inspirarse en ellos y poder positivizarlos.

2. Función interpretativa: implica que al interpretar la norma, el operador debe inspirarse en los principios, para garantizar una cabal interpretación.

3. Función integrativa: significa que quien va a colmar un vacío legal, debe inspirarse en los principios para que el derecho se convierta en un sistema hermético.

Estas funciones no actúan independientemente, sino que en la aplicación del derecho opera una u otra (p. 73).

Para que estos principios tengan valor intrínseco y peso ponderativo deben estar incorporados en la Constitución, "porque si no solo serían meros principios morales y la necesidad de ponderación no sería un postulado jurídico, sino extrajurídico" (Alexy, 2004, p. 74).

Luigi Ferrajoli (1995) estima que los principios generales en un ordenamiento jurídico son principios políticos, expresamente enunciados en las constituciones y leyes o implícitos en ellas y extraíbles mediante elaboración doctrinal ( $p$. 171), representan un factor de racionalización del poder de disposición y limitación del arbitrio (pp.173-174), por lo que señala que los principios de la democracia son "desde el de legalidad hasta el de publicidad y transparencia, el de representatividad, los de responsabilidad política y control popular del funcionamiento del poder" (p. 9).

Se puede concluir que los principios constitucionales son conceptos, directrices o ideas abstractas, que sirven para materializar las funciones y los fines del Estado (Hernández, 1992, p. 7 y ss.).

La selección y materialización de los principios rectores de un Estado sucede a partir de ciertas circunstancias, coyunturas, etc.; esto es lo que permite establecer un sistema político y legal. ${ }^{5}$

Estos principios se depositan en la Constitución para su jerarquización y deben permear la creación, aplicación y resolución de las diversas situaciones que se presentan en las actividades del Estado. ${ }^{6}$

Del estudio de diversas constituciones y de la doctrina se puede advertir que los principios gobernantes más relevantes en materia judicial son: imparcialidad, independencia, legalidad, objetividad y publicidad (Rosales, 2009, p. 307).

El primer principio jurídico que se estudiará es el de la imparcialidad, que se deriva de la apropiada actuación de los jueces y los efectos que deben provocar sus sentencias.

5 Por ejemplo, en el modelo de Estado democrático de Derecho los principios que rigen la administración pública son: probidad, economía, publicidad, rendición de cuentas, eficacia, responsabilidad, participación, legalidad y eficiencia.

6 El modelo de Estado democrático de Derecho es una de las evoluciones histórico-políticas del Estado de derecho (rule of law). Estos valores no solo deben ser rectores de la organización administrativa o de sus decisiones, sino considerarse para las distintas esferas del poder público. Ver definición de "Estado de Derecho", en Enciclopedia Jurídica Mexicana, III, pp. 830-832. 


\section{A. Imparcialidad}

La imparcialidad es definida en el Diccionario de la Lengua Española como: "la falta de designio anticipado o de prevención en favor o en contra de alguien o algo, que permite juzgar o proceder con rectitud".

Isabel Trujillo (2007) entiende la imparcialidad como "la ausencia de todo aquello que puede estorbar el juicio objetivo y, en sentido estricto, sería la ausencia de las pasiones que pueden dificultar una consideración equitativa de las partes" (p. 17).

La imparcialidad se puede considerar un hábito de conducta y de disposición objetiva, que puede obtenerse con el desempeño de las labores, que va madurando con el raciocinio y se coloca por encima de la posición particular y que pone al juzgador por encima de la litis y sometido solo al imperio de la ley (Dromi, 1982, pp. 55-60).

Trujillo valora a primera instancia la imparcialidad desde el punto de vista jurídico: "La imparcialidad se ha configurado tradicionalmente como una característica estructural del derecho. Se sitúa dentro del juicio de autoridad y constituye un criterio interno de articulación, conectado con una exigencia de justicia en relación con los sujetos implicados" (2007, p. 2). Esta autora estima que existen dos conceptos primarios de imparcialidad: "el primero tiene que ver con la objetividad del juicio y considera imparcial a quien juzga de manera objetiva, sin prejuicios o distorsiones; el segundo tiene que ver con el equilibrio cuando se confrontan intereses opuestos, poniendo el acento sobre un sentido colateral de imparcialidad: la ausencia de favoritismo o de partidismo" (p. 3). ${ }^{7}$

Por lo que se deben distinguir tres concepciones de este principio:

1) desde el punto de vista del hombre virtuoso, la imparcialidad consistiría en la capacidad de deliberar bien; 2) la imparcialidad consistiría en la capacidad de deliberar bien en materia de relaciones subjetivas conectadas con la operación de la distribución; es decir, la virtud del que realiza un buen juicio de justicia; $y, 3$ ) la imparcialidad consistiría en una característica de la ley relativa a su justicia y sabiduría" (Saldaña, 2007, p. 30).

De esta manera, se puede observar que la imparcialidad "no es fruto de una elección personal del individuo, como lo sería quizá si fuese una cualidad moral; es obra de una reglamentación que establece funciones y modalidades" (Saldaña, 2007, p. 292).

En materia judicial, la imparcialidad es un producto de la voluntad de decidir o juzgar rectamente, con base en la experiencia, en la capacidad profesional y estar bien informado sobre el negocio que se va a resolver (Galván, 2006, p. 93).

Este principio jurisdiccional se encuentra definido en el Código de Ética del Poder Judicial de la Federación (CEPJF) mexicano, en su artículo $2^{\circ}$, como la "actitud del juzgador frente a influencias extrañas al Derecho, provenientes de las

$7 \quad$ Véase Saldaña, J. (2007, pp. 48-51). 
partes en los procesos sometidos a su potestad. Consiste en juzgar, con ausencia absoluta de designio anticipado o de prevención a favor o en contra de alguno de los justiciables" (2004, p. 18). ${ }^{8}$

Por lo anterior, el principio de imparcialidad significa que, en el desarrollo de sus actividades, todas las autoridades jurisdiccionales deben reconocer y velar permanentemente por el interés de la sociedad y por los valores fundamentales de la democracia supeditando a estos, de manera irrestricta, cualquier interés personal o preferencia política (TEP JF, 2003, p. 15).

La imparcialidad del juzgador no es un gesto o un favorecimiento hacia la víctima o el procesado, sino un principio judicial para que no exista ningún tipo de apoyo y poder conservar el equilibrio procesal, que permitirá que la impartición de justicia no se encuentre viciada o cooptada por ningún elemento o hecho que provoque cualquier parcialidad.

Las materias primas para un juicio imparcial son: la independencia, la legalidad y la estabilidad en su cargo del juez. A continuación se analizará el principio de independencia en dos vertientes, como principio institucional y como principio garante del sistema de administración de justicia.

En el caso particular de la imparcialidad como trato digno a la víctima, se refiere a no tomar una posición que desequilibre los derechos de

8 Véase Trujillo (2007, pp. 360-381). las partes pues toda parcialidad rompe la igualdad procesal. Lo que se propone es que el juez otorgue garantías y certidumbre con base en su imparcialidad, y con esto genere respeto a las víctimas, así como a los procesados.

\section{B. Independencia}

En la actualidad, las democracias constitucionales occidentales comparten una característica fundamental: la independencia del juez, o sea, un conjunto de garantías destinadas a asegurar su imparcialidad respecto a las partes y a las instituciones políticas y sociales (Guarnieri y Pederlozi, 1999, p. 16).

De manera particular, la independencia judicial es la nota que no puede conseguirse más que con la seguridad en el desempeño laboral de los juzgadores, proveniente de la certeza del nombramiento y de saberse sujetos a la promoción, y con la adecuada retribución y estímulos que les brinde tranquilidad personal, lo que en su conjunto significará la existencia de un poder judicial que no guarde dependencia en ningún sentido, y mucho menos de relación de jerarquía alguna con los funcionarios de los otros poderes públicos, a fin de estar en la capacidad de cumplir con el papel que la Constitución les ha asignado (Herrendorf, 1994, pp. 97-109).

La independencia jurisdiccional significa que los jueces no se encuentran sometidos a ninguna instancia jerárquica, política, administrativa, económica, burocrática o de cualquier orden, pues la esencia del ejercicio de su función es la libertad para actuar, sin tomar en cuenta ningún 
elemento que no sea la ley (Melgar, 2000, p. 29). Esta garantía judicial tiene por objeto conservar su imparcialidad y mantener ajenos de cualquier influencia a los servidores del poder judicial (Guarnieri y Pederzoli, 1999, p. 17).

La subordinación del juez es solo a la ley y esto es, precisamente, su protección más eficaz y su garantía para una independencia judicial plena: "La amplitud y la efectividad de las garantías personales que rodean al juez están estrechamente conectadas con las características particulares de la organización judicial que, en gran medida son tributarias del tipo de reclutamiento" (Guarnieri y Pederzoli, 1999, p. 46).

La racionalidad que subyace al principio de independencia judicial es, sin duda, la necesidad de contar con una auténtica imparcialidad en la administración de justicia. No solo para proteger a los individuos en contra de cualquier tipo de arbitrariedad o abuso, sino, sobre todo, para permitir que solo sea un órgano imparcial, el autorizado para determinar el sentido de la norma jurídica (Caballero y Concha, 2002, p. 309).

Las injerencias a la labor judicial pueden ser externas o internas:

La independencia exterior se plantea ante los otros poderes formales. El Judicial -o jurisdiccional- no depende del Ejecutivo ni del Legislativo en el cumplimiento de las facultades que le reserva la Constitución Política, con base en la división de poderes. La independencia interior se presenta cuando el juzgador está en posibilidad de conocer o resolver sin que lo distraigan circunstancias propias -oriundas, a menudo, de sus relaciones o situaciones personales- que pudieran desviar la legitimidad del juicio (García, 1997, pp. 30-31). ${ }^{9}$

El principio de independencia es definido por el Código de Ética del Poder Judicial de la Federación, como la "actitud del juzgador frente a influencias extrañas al derecho, provenientes del sistema social. Consiste en juzgar desde la perspectiva del Derecho y no a partir de presiones o intereses extraños a aquél" (2004, p. 17).

La independencia judicial hace referencia a las garantías y atributos de que disponen los órganos y autoridades que conforman el tribunal, para que sus procesos de deliberación y toma de decisiones se den con absoluta libertad y respondan única y exclusivamente al imperio de la ley, afirmándose su total independencia respecto de cualquier poder establecido (TEP JF, 2003, pp. 14-15). ${ }^{10}$

Asimismo, el principio de independencia significa "libertad en el sentido de ausencia de subordinación. Entonces, la autoridad debe resolver de manera libre, sin aceptar ningún tipo de injerencia en la toma de sus decisiones jurisdiccionales, sea de poderes públicos o de cualquier tipo de personas, organizaciones y entes políticos" (Canto, 2008, p. 49).

Al brindar independencia a los juzgadores se gestiona su imparcialidad, manteniendo un orden democrático institucional, por lo que es

9 El principio de independencia forma parte de las llamadas garantías jurisdiccionales.

10 Véase Nieto (2003, p. 308) 
determinante contar con autoridades independientes para desaparecer cualquier duda en su actuación y, sobre todo, garantizar las condiciones para un óptimo desempeño.

Para Negretto y Ungar (1997) la finalidad de la independencia del poder judicial es proveer un "sistema de garantías mutuas, para evitar la posibilidad de que un actor sea capaz de manipular unilateralmente las reglas del sistema político" (p. 83). Se deduce, entonces, que la independencia judicial depende de los valores éticos y de la formación del juzgador, “de ahí emanan todas las determinaciones del impartidor de justicia" (p. 94). ${ }^{11}$

La independencia judicial asegurará que la magistratura no se encuentre sujeta a ningún elemento interno o externo en sus actuaciones. En el caso de la víctima, le generará confianza en el sistema de administración de justicia y, sobre todo, que sienta que el juez no se encuentra supeditado a intereses o favores que afectarían al justiciable.

Uno de los pilares del Estado de Derecho es la aplicación de la norma al caso, lo que permite que los ciudadanos cuenten con sentencias basadas en leyes previamente establecidas, generando seguridad a los justiciables.

En el caso de las víctimas, si el personal judicial o administrativo no es independiente sus decisiones causarán un daño a los justiciables. Por

11 Por ejemplo, a la Corte Warren se la ha considerado liberal, mientras que la Corte encabezada por Rehnquist ha sostenido una tendencia conservadora (Wolfe, 1994, pp. 258-291). eso la independencia es un valor imprescindible para la impartición de justicia, en el que la víctima deposita su confianza para alcanzar la reparación del daño y la sanción al victimario.

\section{Legalidad}

La legalidad, según el Diccionario de la Lengua Española es un término que alude a la "cualidad de legal" y en Derecho significa "ordenamiento jurídico vigente". Así, el principio de legalidad es allí mismo definido como: "el principio jurídico en virtud del cual los ciudadanos y todos los poderes públicos están sometidos a las leyes y al derecho".

Considerar el principio de legalidad conlleva, lógicamente, a su manifestación material, el denominado estado de Derecho. ${ }^{12}$

En general, por "estado de Derecho" (rule of law $)^{13}$ se entiende, básicamente, aquel Estado cuyos diversos órganos e individuos miembros se encuentran regidos por el derecho y sometidos al mismo. Para el profesor Jesús Orozco (2006) este concepto denota que el "poder y la actividad estatal están regulados y controlados por el derecho. En este sentido, el Estado de Derecho contrasta con todo poder arbitrario y, a su

12 Para Carl Schmitt, el estado de Derecho es característico de todo Estado que respete sin condiciones el derecho objetivo vigente y los derechos subjetivos que existan (1966, p. 150).

13 Dicey introdujo al common law inglés el modelo de sometimiento de la administración al derecho, denominándolo rule of law, en su obra Introduction of the study of the law of the Constitution aparecida en 1855. En su opinión, el rule of law expresa, entre otras cosas, la idea de la igualdad formal ante la ley y la negación de cualquier privilegio a la ley (Escuin, 2004, pp. 25 y 26). 
vez, se contrapone a cualquier forma de Estado absoluto o totalitario" (p. 122).

El modelo de Estado de Derecho se conforma de diversos elementos, entre los que destacan: “la soberanía popular; la división de poderes; el principio de legalidad y el reconocimiento de los derechos fundamentales del ciudadano" (Cosculluela, 2004, p. 21).

El concepto de ley propio del Estado de Derecho, que transforma al imperio de la ley, exige que el gobierno sea quien esté sujeto a la ley, antes que la ley sea sometida por el gobierno (Wade, 1971, p. 18); por tanto, la legalidad será el quid de toda actividad del poder público y su actuación deberá estar fundada y motivada en el ordenamiento legal.

La historia del Estado de Derecho puede ser leída como una progresiva minimización del poder por la vía de su regulación jurídica (Ferrajoli, 2008, p. 208).

La actuación del juzgador siempre deberá ser con base en la ley (legalidad), o lo que otros han llamado el gobierno de los jueces, donde la norma jurídica significa la base de las instituciones.

El principio de legalidad limita la acción de las autoridades en un gobierno constitucional y, al mismo tiempo, debe servir como cimiento a toda la estructura del Estado (Hamilton, Madison y Jay, 2006, p. 22). Por lo que la legalidad se sustenta en que la autoridad solo está facultada a actuar en la forma que señala la norma jurídica, y a cumplir las leyes cabalmente.
La legalidad involucra que:

todo acto de la autoridad debe encontrarse motivado y fundado en una norma en sentido material, es decir, general, abstracta e impersonal, expedida con anterioridad a los hechos sujetos a estudio. En este sentido, para el ejercicio de las atribuciones y el desempeño de las funciones que tienen encomendadas las autoridades, se deben observar escrupulosamente el mandato constitucional que las delimita, los tratados internacionales aplicables a la materia y las disposiciones legales que las reglamentan (Canto, 2008, p. 57).

La base de este principio exige que "la función jurisdiccional ciña su marco de actuación a la normatividad constitucional y legal que regula su organización, atribuciones, funcionamiento y competencia" (Cienfuegos, 2008, p. 101). ${ }^{14}$

Leoncio Lara define el principio de legalidad en cuanto a sus objetivos: "conlleva a que el Tribunal en el cumplimiento de sus fines y en el ejercicio de sus atribuciones cumpla de manera absoluta con las disposiciones constitucionales y legales que lo configuran y lo delimitan, en especial con los ordenamientos jurídicos" (2003, pp. 39-40). ${ }^{15}$

La debida aplicación de la normatividad conlleva que se lleven los procesos de manera adecuada. Esto significa que un justiciable podrá hacer valer sus derechos y defender sus intereses en forma efectiva y en condiciones de

\footnotetext{
14 Véase Galván (2006, pp. 90-91).

15 Véase Galván (2006, pp. 90-91).
} 
igualdad procesal con otros justiciables, por lo que es preciso que para que haya un proceso deben existir verdaderas garantías judiciales; "observar todos los requisitos que sirvan para proteger, asegurar o hacer valer la titularidad o el ejercicio de un derecho, es decir, las condiciones que deben cumplirse para asegurar la adecuada defensa de aquellos cuyos derechos u obligaciones están bajo consideración judicial" (Caso Hilaire, Constantine y otros vs. Trinidad y Tobago, 2002, p. 145). ${ }^{16}$

Este principio es muy importante pues en la medida en que un proceso se acerque más a la legalidad, más próximo estará de alcanzar la justicia. A su vez, la víctima tiene derechos sustantivos (asistencia médica, psicológica, legal, entre otros) y adjetivos (participación activa en el proceso) que deberá proteger y procurar el sistema de impartición de justicia.

A continuación se analizará otro principio que debe regir la actuación del juez: la objetividad.

\section{Objetividad}

El Diccionario de la Lengua Española define objetividad como "la cualidad de objetivo" y objetivo como: "perteneciente o relativo al objeto en sí mismo, con independencia de la propia manera de pensar o de sentir. Desinteresado, desapasionado". ${ }^{17}$

16 Véase Alvarado (2000).

17 Véase también Tribe (1991, p. 67).
Ronald Dworkin considera la objetividad como la cualidad suficiente y plena de la interpretación de la ley y de comprobación de los hechos contrastados por las partes, despejada hasta lo humanamente posible de cualquier asomo de subjetividad o de relatividad que pueda entorpecer la función del juzgador, en agravio de la impartición de justicia (1995, pp. 154 y ss.).

El principio de objetividad relaciona un quehacer institucional y personal fundado en el reconocimiento global, coherente y razonado de la realidad sobre la que se actúa y, consecuentemente, la obligación de percibir e interpretar los hechos por encima de las visiones y opiniones parciales o unilaterales, máxime si estas pueden alterar la expresión o consecuencia del quehacer institucional del tribunal (TEP JF, 2003, p. 15).

En materia judicial, este principio significa "que la autoridad debe basar su actuación en hechos debidamente demostrados y tangiblemente admitidos, sin que quepa la posibilidad de que sus miembros actúen con base en impulsos o apreciaciones subjetivas, exige por tanto la necesidad de elementos de constatación para cualquier observador externo" (Cienfuegos, 2008, p. 101).

El artículo 3 del CEPJF define el principio de objetividad judicial como la "actitud del juzgador frente a influencias extrañas al Derecho, provenientes de sí mismo. Consiste en emitir sus faIlos por las razones que el Derecho le suministra y no por las que se deriven de su modo personal de pensar o de sentir". 
Este principio genera que el juzgador se despoje de sus ideas, gustos, pasiones y convicciones al momento de actuar. En el ámbito de su función, la autoridad debe colocar una barrera entre su personalidad y su trabajo profesional, sin favoritismos que puedan afectar el debido proceso o su sentencia.

La objetividad es una virtud que le permite al juez manejar correctamente el proceso, sin preferencias, gustos o razones subjetivas a favor de alguna de las partes. Por supuesto, actuar con objetividad le implica separarse en parte de su personalidad para subsumirla con profesionalismo jurídico.

Otro principio fundamental para una buena y sana impartición de justicia es el de publicidad.

\section{E. Publicidad}

El Diccionario de la Lengua Española presenta las siguientes acepciones para el término publicidad: "cualidad o estado de público//conjunto de medios que se emplean para divulgar o extender la noticia de las cosas o de los hechos".

La incorporación de la sociedad a la política creó “el interés público, las libertades públicas, la seguridad pública y la opinión pública" (Cabo de la Vega, 1997, p. 67) y redimensionó el principio de publicidad.

Ernesto Garzón Valdés estima que "la publicidad es un principio normativo [que] puede servir como criterio para juzgar acerca de la calidad democrática de un sistema político: cuando está presente se habla de razón de derecho, cuando está ausente, de razón de Estado" (citado por Doublet, 2003, p. 494). ${ }^{18}$

El carácter público de los actos del Estado viene determinado por la función que desempeñan dichos actos. "Si se trata de actos realizados íntegra o exclusivamente como consecuencia de la existencia y funciones del Estado o que tengan como causa inmediata la satisfacción de un determinado interés colectivo, dichos actos son públicos" (Carpizo, 2007, p. 107).

Cabo de la Vega distingue dos distintos tipos de publicidad: “1. la que la relaciona con el Estado (es público todo aquello que directa o indirectamente es del Estado, es decir, la publicidad en sentido orgánico) y 2 . Aquí, lo público, como la razón última de la naturaleza pública del acto y de la actividad del Estado es la de satisfacer los intereses colectivos del pueblo" (1997, pp. 159-161).

De esta manera, lo público se concibe como una interrelación entre lo público de la sociedad y lo público del Estado, siendo la sociedad la encargada de trasladar y especificar el interés nacional a la esfera estatal (Cabo de la Vega, 1997, p. 199).

Un aspecto fundamental aunado a la publicidad es la transparencia. Ambos conceptos se confunden por su familiaridad, además, en bastantes ocasiones se han entendido y utilizado como

18 La publicidad puede ser clasificada como: especialidad orgánica, como garantía, como interés y como ámbito (Cabo de la Vega, 1997, p. 67). 
sinónimos, por lo que es necesario discernir cada uno de ellos.

La transparencia es definida como "cualidad de transparente". A su vez, transparente significa: "que se deja adivinar o vislumbrar sin declararse o manifestarse//claro, evidente que se comprende sin duda ni ambigüedad" (Diccionario de la Lengua Española, 2001).

En su sentido jurídico, la transparencia es el derecho de los ciudadanos a conocer y analizar las actividades estatales, garantía de control que los acerca más a la justicia y al desarrollo social y, por tanto, al fortalecimiento del Estado (Villanueva, 2002, pp. 25-40).

De manera general, la transparencia viene a ser la actitud o actuación pública que deja ver claramente la realidad de los hechos y actos públicos. En consecuencia, es aquello que nos permite apreciar con nitidez en el orden jurídico lo que realiza el Estado. La transparencia, en una sociedad abierta, garantiza el libre acceso a la información, favoreciendo de ese modo la claridad del poder (Villanueva, 2002, pp. 40-42).

En materia de transparencia, lo importante no es el "qué" se hace, si no el "cómo" se hace, puesto que debe permitir aclarar las dudas en materia pública y, sobre todo, vigilar la actuación del gobierno (Garapón, 1997, p. 83).

La transparencia se puede materializar de tres diferentes maneras: a solicitud personal, por ministerio de ley y por mutuo consentimiento. En el primer caso, el solicitante, ya sea persona física o jurídica, debe tramitar su solicitud en el lugar correspondiente, bajo los procesos y mecanismos de forma y de fondo que estén indicados. ${ }^{19}$ En el segundo caso, las autoridades deben hacer pública la información que señale la ley (por ejemplo, salarios, licitaciones, compras, etc.). En el tercer caso, referido a instituciones privadas que no tengan la obligación de transparencia, estas pueden divulgar sus trabajos, administración de recursos, reglamentos, etc., con el objetivo de legitimar su actuación. ${ }^{20}$

La transparencia se ha colocado en la categoría de lo políticamente correcto; pero aún está lejos de alcanzar tal reconocimiento en las prácticas burocráticas cotidianas. Y esto se debe, entre otras causas, a que la transformación cultural de aceptar, comprender y asimilar la transparencia como condición consubstancial del quehacer público tomará algunas generaciones (Bonilla, 2008, p. 12).

El principio de publicidad de los actos públicos conlleva transparencia de las actuaciones, claridad en las labores y genera la entrega y justificación en la rendición de cuentas.

La rendición de cuentas se erige como un medio de control del poder, con miras a limitar y prevenir los abusos en el ejercicio de este, que busca

19 Al gozar los ciudadanos del derecho a la información, la finalidad de este principio es proveer lo necesario para garantizar el acceso de toda persona a la información en poder de los entes públicos, los órganos constitucionales autónomos o con autonomía y cualquier otra entidad pública; estableciéndose de antemano el titular del derecho y los sujetos obligados a cumplir esa prerrogativa (Castillo, 2006, p. 257).

20 Estos tres mecanismos sirven para poner a disposición de la población diversa información. En general, podríamos considerar a la publicidad como el género y a la transparencia como la especie. 
equilibrar su permanencia, vigencia e inclusive alternancia como resultado de los incesantes, vibrantes, quizá heroicos y tan sangrientos excesos que engrosan el mar histórico que le comprende. Monitorea además a las autoridades en el cumplimiento de la ley, acción que abarca en una forma amplia tres grandes puntos: el derecho a la información, la justificación y en su caso las sanciones o castigos.

De esta manera, en un Estado constitucional de Derecho resulta imperativo el compromiso de maximizar la transparencia y la rendición de cuentas, como condiciones básicas de la democracia.

La publicidad y la transparencia permitirán que la víctima pueda participar, vigilar y controlar las actuaciones judiciales. Esto no es un beneficio exclusivo hacia las partes en conflicto, también permitirá que la magistratura legitime su papel frente a la sociedad, al conocerse su actuación.

\section{CONCLUSIONES}

1. El Estado tiene como principio fundacional brindar seguridad y una debida impartición de justicia a la población. El instrumento por excelencia con que cuenta para estos cometidos es el establecimiento de un poder judicial compuesto por tribunales y jueces.

2. Los tribunales están comprometidos y gobernados con base en la legalidad, pues el Derecho es un medio, y la justicia un anhelo social. Pero no es suficiente poseer normas; el poder judi- cial debe estar reconocido y articulado con los demás poderes políticos (ejecutivo y legislativo). Para ejercer sus funciones necesita contar, en primer plano, con jurisdicción (reconocimiento institucional y funcional), y su acción deberá apegarse a un conjunto de principios que dirijan su actuación al impartir justicia.

3. Los principios rectores judiciales son lineamientos que sirven para que los tribunales puedan actuar de manera autónoma, de modo que su acción no esté subordinada a nada ni a nadie; garantizar a las partes los mismos derechos y obligaciones, con imparcialidad, sin preferencias o favoritismos en las sentencias; sus actuaciones sean conocidas; sus resoluciones no contengan ningún sesgo de su personalidad o gustos y, sobre todo, se apeguen lo más posible a la normatividad para estar más cerca de la justicia.

4. La imparcialidad tiene relación con la independencia. Si el juez es imparcial se debe a su independencia, misma que le permite emitir resoluciones sin carga, favoritismo o indicación de terceros. La independencia, entonces, es una condición para que el juez sea imparcial (Orozco, citado en Vásquez, 2007, p. 89). La publicidad de los actos permite vigilar la actuación de las autoridades, y en el caso de los jueces, observar que se sujeten al principio de legalidad al fundar y motivar sus resoluciones, es decir, si se han apegado al marco jurídico (Cabo de la Vega, 1997, p. 89).

5. La certeza judicial nace por la necesidad de los ciudadanos y de todos los actores políticos 
de tener garantizados sus derechos y de confiar en las resoluciones de los jueces. ${ }^{21}$

6. Los jueces son los responsables de la conservación del Estado social y democrático de Derecho. Tienen el deber de restablecer el imperio de la norma, y hacer que la sociedad sienta que sus derechos serán respetados y protegidos (Bobbio, 1986, pp. 30-33).

Pero no es suficiente que los jueces satisfagan los requisitos constitucionales y legales al cumplir con su labor; además, deben tener legitimidad en su función jurisdiccional (Orozco, 2006, p. 101. En la mayoría de los casos, los magistrados carecen de legitimidad democrática, por lo que deben obtenerla al momento y en la forma en que apliquen las normas (Yackle, 2007, p. 80).

Sin embargo, la aplicación de las leyes produce exclusivamente legalidad, no legitimidad; esta última deviene de la forma como justifiquen sus decisiones, y de cómo esa justificación es percibida, entendida y aceptada por la comunidad (Nieto, 2003, pp. 4 y 294). Por consiguiente, las sentencias no solo deben estar fundadas y motivadas, también "deben responder a una verdadera interpretación de la Constitución, para que puedan generar legitimidad en la sociedad" (Courtis, 2005, p. 18).

7. Sin duda, la víctima tiene derecho a contar con un trato especializado por el impacto, el

21 La Suprema Corte de Justicia de México ha manifestado que el principio de certeza permite y garantiza que "todos los participantes en el proceso electoral, conozcan con claridad y seguridad, las reglas a que están sujetas en su actuación las autoridades electorales". Sentencia relativa a la acción de inconstitucionalidad 18/2001 y sus acumuladas $19 / 2001$ y $20 / 2001$. daño y el menoscabo que vivió, así como por las secuelas subsecuentes. En estos casos, el juzgador debe considerar y ponderar su situación durante el proceso; dirigir procedimientos y aplicar protocolos de actuación para que esto sea lo menos doloroso y traumático, pero con el cuidado de no producir un trato preferente. Se trata, en definitiva, de generar un proceso que sea más próximo y justo para la víctima, y que la persona obtenga una reparación del daño que le permita recobrar su calidad de vida.

8. Brindar un buen trato a la víctima implica también reducir la revictimización, es decir, los efectos de revivir, una vez se inicia el proceso legal, el hecho sufrido. Estas experiencias pueden incluso aumentar las consecuencias provocadas por el delito en sí, además de vivir otro tipo de maltrato: el institucional (Marchiori, 1998).

9. La creación y difusión de protocolos de investigación para el tratamiento de las víctimas constituye un elemento primordial para asegurar que la persona cuente con la asistencia necesaria y que conozca sus derechos (Doerner y Lab, 2008). Asimismo, se debe establecer un sistema de preparación para todas las autoridades públicas, de modo que estén enteradas de la conducta y de la ética que deben seguir con todos los justiciables.

10. El personal responsable de proporcionar la atención integral (trabajo social, psicológico, legal y médico) a las víctimas debe contar con conocimientos especializados y ser seleccionado con base en su experiencia. Esto con el fin de proveer atención e información clara y consis- 
tente que apoye y guíe a la víctima, para que esta perciba un ambiente profesional que, sin duda, influirá en la decisión de continuar en el proceso hasta su fin. También, es fundamental que los servidores públicos que tienen contacto con la víctima reciban una constante y adecuada capacitación, para que posean los conocimientos y lineamientos necesarios y vigentes.

\section{Referencias}

Acciones de inconstitucionalidad 18/2001, $19 / 2001$ y $20 / 2001$. Suprema Corte de Justicia de México.

Alexy, R. (2004). El concepto y la validez del derecho. Barcelona: Editorial Gedisa.

Alvarado Velloso, A. (2002). El debido proceso de la garantía constitucional. Santa Fe: Zeus.

Andrade Martínez, V. (2002). Balance y perspectivas de la justicia electoral en México. En E. Elías Musi (Coord.), Evolución histórica de las instituciones de la justicia electoral en México (págs. 599-641). México: Tribunal Electoral del Poder Judicial de la Federación.

Ansolabehere, K. (2007). La política desde la justicia. Cortes supremas, gobierno y democracia en Argentina y México. México: Fontamara.

Arellano García, C. (1992). Teoría general del proceso. México: Editorial Porrúa.
Atienza, M. (2005). Las razones del derecho. Teorías de la argumentación jurídica. México: Universidad Nacional Autónoma de México.

Barreiro Pereira, F. J. (1999). Garantías de los órganos encargados de la administración de justicia electoral federal en México. En Sistemas de justicia electoral. México, D. F.: TEPJF.

Bix, B. H. (2004). Jurisprudence. Theory and Context. Durham, North Carolina: Carolina Academic Press.

Bix, B. H. (2009). Diccionario de teoría jurídica. México: unam.

Bobbio, N. y Bovero, M. (1986). Origen y fundamentos del poder político. México: Grijalbo.

Bonilla Núñez, S. (Diciembre, 2008). Derecho de acceso a la información pública. Un derecho en construcción. Justicia. Punto de Equilibrio (pp. 22-25).

Caballero Juárez, J. A. y Concha Cantú, H. A. (2001). Diagnóstico sobre la administración de justicia en las entidades federativas. México: National Center for State Courts, Instituto de Investigaciones Jurídicas, Universidad Nacional Autónoma de México.

Cabo de la Vega. A. (1997). Lo público como supuesto constitucional. México: Universidad Nacional Autónoma de México.

Canto Presuel, J. (2008). Diccionario electoral. México: Teqroo. 
Carpizo, J. (2007). Concepto de democracia y sistema de gobierno en América Latina. México: Universidad Nacional Autónoma de México.

Castillo González, L. (2006). Reflexiones temáticas sobre derecho electoral. México: Tribunal Electoral del Poder Judicial de la Federación.

Chiovenda, G. (1989). Instituciones de derecho procesal civil, (Vol. II). México: Ed. Cárdenas.

Cienfuegos Salgado, D. (2008). Justicia y democracia: apuntes sobre temas electorales. México: Universidad Autónoma de Chiapas, Centro de Estudios Estatal y Municipal y El Colegio de Guerrero.

Corte Interamericana de Derechos Humanos. (21 de junio del 2002). Caso Hilaire, Constantine y otros vs. Trinidad y Tobago.

Cosculluela Montaner, L. (2004). Manual de derecho administrativo, (Vol. I). Madrid: Civitas.

Courtis, C. (Mayo, 2005). La legitimidad del poder judicial ante la ciudadanía. Nexos, 329.

De la Mirándola, J. P. (1984). De la dignidad del hombre. Madrid: Editora Nacional.

De Pina, R., Castillo Larrañaga, J. y de Pina Vara, R. (1982). Instituciones de derecho procesal civil. México: Editorial Porrúa.

Doerner, W. y Lab, S. (2008). Victimology. Uni- ted States: LexisNexis.

Doublet, Y. (2003). Financiamiento, corrupción y gobierno. En Dinero y contienda políticoelectoral. México, D. F.: Fondo de Cultura Económica.

Dromi, J. R. (1982). El poder judicial. Tucumán: Ediciones UNSTA.

Dworkin, R. (1995). Los derechos en serio. Barcelona: Ariel.

Escuin Palop, C. (2004). Curso de derecho administrativo. Valencia: Tirant lo Blanch.

Ferrajoli, L. (1995). Derecho y razón: teoría del garantismo penal. Madrid: Editorial Trotta.

Ferrajoli, L. (2008). Democracia y garantismo. Madrid: Editorial Trotta.

Galván Rivera, F. (2006). Derecho procesal electoral mexicano. México: Editorial Porrúa.

Garapón, A. (1997). Juez y democracia. Barcelona: Flor del Viento.

García Ramírez, S. (1997). Poder judicial y ministerio público. México: Editorial Porrúa.

Guarnieri, C., Pederzoli, P. y Ruiz de Azúa, M. (1999). Los jueces y la política: poder judicial y democracia. Madrid: Taurus.

Hamilton, A., Madison, J. y Jay, J. (2006). El Federalista. México: Fondo de Cultura Económica. 
Hernández Valle, R. (1992). Los principios constitucionales. Costa Rica: Corte Superior de Justicia. Escuela Judicial.

Herrendorf, D. E. (1994). El poder de los jueces: cómo piensan los jueces, qué piensan. Buenos Aires: Abeledo-Perrot.

Instituto de Investigaciones Jurídicas. Universidad Nacional Autónoma de México. (2002). Enciclopedia Jurídica Mexicana. México, D. F.: Porrúa, S. A.

Lara Sáenz, L. (2003). Derechos humanos y justicia electoral. En Colección de cuadernos de divulgación sobre aspectos doctrinarios de la justicia electoral, (4), 1-59. México: Tribunal Electoral del Poder Judicial de la Federación.

Lowenstein, K. (1964). Teoría de la Constitución. Barcelona: Ariel.

Marchiori, H. (1998). Criminología: la víctima del delito. México: Editorial Porrúa.

Melgar Adalid, M. (2000). El Consejo de la Judicatura Federal. México: Editorial Porrúa.

Negretto, G. y Ungar, M. (1997). Independencia del poder judicial y Estado de Derecho en América Latina. Política y Gobierno, IV, 81114.

Nieto, S. (2003). Interpretación y argumentación jurídicas en materia electoral: una propuesta garantista. México: unAm, Instituto de Investigaciones Jurídicas.
Orozco Henríquez, J. (2006). Justicia electoral y garantismo jurídico México: Editorial Porrúa.

Pérez Luño, A. E. (1991). La seguridad jurídica. Barcelona: Ariel.

Ponce de León Armenta, L. (1997). Derecho político electoral. México: Editorial Porrúa.

Robertson, D. (1997). A dictionary of human rights. London: Europa Publications.

Rosales, C. M. (Enero-julio, 2009). Principios rectores en materia electoral en Latinoamérica. Revista IIDH, (49), 265-311.

Salazar, P. (2007). La laicidad: antídoto contra la discriminación. México: Consejo Nacional para Prevenir la Discriminación.

Saldaña Serrano, J. (2007). Ética judicial: virtudes del juzgador. México: Suprema Corte de Justicia de la Nación.

Schmitt, C. (1966). Teoría de la Constitución. México: Editora Nacional.

Suprema Corte de Justicia de la Nación. (2004). Código de Ética del Poder Judicial de la Federación. México, D. F.: Autor.

Tribe, L. H. (1991). On Reading the Constitution. Cambridge, Massachusetts: Harvard University Press.

Tribunal Electoral del Poder Judicial de la Federación. (2003). El sistema mexicano de justicia electoral. México: TEP JF. 
Trujillo, I. (2007). Imparcialidad. México: Universidad Nacional Autónoma de México.

Vázquez, R. (Comp.). (2007). Corte, jueces y política. México: Fontamara.

Villanueva, E. (2002). Derecho de acceso a la información pública estatal: una aproximación al estado de la cuestión en México. México: Universidad Nacional Autónoma de México, Instituto de Investigaciones Jurídicas.

Wade, H. W. (1971). Derecho administrativo. Madrid: Instituto de Estudios Políticos.

Wolfe, C. (1994). The Rise of Modern Judicial Review: From Constitutional Interpretation to JudgeMade Law. Boston: Littlefield Adams Quality Paperbacks.

Yackle, L. (2007). Regulatory Rights. Chicago: University of Chicago Press.

Zamora Grant, J. (2009). Derecho victimal: la víctima en el nuevo sistema penal mexicano. México: Instituto Nacional de Ciencias Penales. 